\title{
SPORTANTHROPOLOGICAL AND SPORTS TRAUMATOLOGICAL ASPECTS OF WOMEN'S SOCCER
}

\author{
Yvonne Voss, Christoph RaschKa \\ Institute of Sports Sciences, Julius-Maximilians-University, Germany
}

\begin{abstract}
The aim of the study is to improve talent search, training methodology and injury prevention in women's soccer. It analyses to what extent there are physical differences between top female soccer players (S) and a control group of sporty females ( $\mathrm{ff}=$ fitness females). Furthermore, it examines whether differences in injuries can be identified between individual game positions (defense, midfield, forward, goalkeeper) and/or somatotypes. For this purpose, the anthropometric measurements of 233 top female soccer players (Ø 22 years old) and 40 fitness females ( $\varnothing 25$ years old) who had been doing regular strength/endurance training twice a week for 2 years were statistically recorded, evaluated and used for determination of constitutional types according to Heath and Carter, Conrad and Knussmann and the AKS index according to Tittel and Wutscherk.

In addition, body fat percentage according to Siri and the body mass index (BMI) were calculated. For the sample of soccer players, the types of injuries (categories: cruciate ligament, other knee, ankle joint/foot, shoulder/torso/hip, other injuries) and injury frequency according to the game positions, somatotypes and various body mass indices were compared statistically. There were significant differences between the anthropometric measurements of pelvic circumference (S: $81.2 \pm 4.3 \mathrm{~cm}$; ff: $95.7 \pm 7.7 \mathrm{~cm}$; $\mathrm{p} \leq 0.001)$ and maximum femoral circumference ( $\mathrm{S}: 54.1 \pm 3.1 \mathrm{~cm}$; ff: $51.1 \pm 4.4 \mathrm{~cm}$; $\mathrm{p} \leq 0.001)$.

In terms of kinanthropometry, there were significant differences in the somatochart according to Heath and Carter [9] (S: 4/5/2; ff: 6/5/3), in the checkerboard pattern according to Conrad [3] (S: leptomorphic/hyperplastic; ff: metromorphic/hyperplastic) and in body fat percentage (S: $18.1 \pm 2.1 \%$; F: $25.0 \pm 4.3 \% ; \mathrm{p} \leq 0.001)$. The goalkeepers differed significantly from the field players with higher heights, lengths, sizes, higher body weight and a higher proportion of other injuries (e.g. hand, arm and head injuries).
\end{abstract}


In constitutional terms, they differed only slightly from the field players. These appeared homogeneous in terms of body structure and injury mechanisms.

Keywords: female soccer players; constitutional types; position; injuries

\section{INTRODUCTION}

Women's soccer is enjoying increasing popularity, especially in Germany. The German national team can look back on a successful series of six European Championships and one World Cup title since 1995. Despite increasing professionalism, there is still a lot of catching up to do in terms of women's soccer-specific research to improve talent search and talent promotion, training methodology and injury prevention.

\section{RESEARCH QUESTIONS}

1. Which is the extent of physical differences between female soccer players and a control group of average physically active women (fitness females)?

2. To which extent do physical differences exist between individual playing positions (defense, midfield, forward, goalkeeper)?

3. Which is the extent of correlation between the individual playing positions respective to different constitution types / body mass indices regarding the injuries suffered?

\section{METHODOLOGY}

This research paper analyses if female soccer players have specific constitutional characteristics in comparison to average physically active women (fitness females). 233 female soccer players from the 1st German Bundesliga teams and the national team of the German Football Association (season 2012/2013) were anthropologically measured. The average age was $22 \pm 4$ years. The data was clustered by playing positions: defense $(n=77)$, midfield $(n=92)$, forward $(\mathrm{n}=40)$ and goalkeeper $(\mathrm{n}=24)$. The control group of fitness females consisted of 40 women from a gymnasium in Frankfurt with no competitive sport experience but a regular workout experience twice a week for at least two years. Their average age was $25 \pm 4$ years. 
63 anthropometric measurements (height, width, length, depth, circumference and body fat content) per participant were determined and statistically evaluated by $\mathrm{IBM}^{\oplus}$ SPSS Statistics ${ }^{\oplus}$. The classification of the constitution types was based on the theories of Heath and Carter [9], Conrad [3] and Knussmann [11] and the AKS index according to Tittel and Wutscherk [16]. Body composition was determined by using callipers and the formulas according to Siri and the calculation of the BMI.

Further, it was examined whether different constitution types and/or types of injuries and injury frequencies can be associated with the individual playing positions of the female soccer players. A history of injuries during the individual soccer career was recorded and divided into 5 categories: cruciate ligament injuries, other knee injuries, ankle joint/foot injuries, shoulder/torso/hip injuries and other injuries (for example hand, arm and head injuries). There was also a classification into "all injuries" and "severest injury" measured by time lost due to injury per female soccer player. Statistical correlations between injury categories and playing positions, constitution types according to Heath and Carter [9], Conrad [3] and Knussmann [11] and the BMI were checked by using cross tables and the $\mathrm{Chi}^{2}$ test.

\section{RESULTS}

\subsection{Anthropological measurements}

The pelvic circumference was significantly different $(\mathrm{p} \leq 0.001)$ with an average of $95.7 \pm 7.7 \mathrm{~cm}$ of the fitness females compared to $81.2 \pm 4.3 \mathrm{~cm}$ of the female soccer players. There was also a difference $(\mathrm{p} \leq 0.001)$ in max. femoral circumference, which was significantly higher in the female soccer players $(54.1 \pm 3.1 \mathrm{~cm})$ than in the fitness females $(51.1 \pm 4.4 \mathrm{~cm})$.

Significant differences were found in the subjects' body fat values. The average body fat content of the fitness females at $25.0 \pm 4.3 \%$ was significantly higher $(\mathrm{p} \leq 0.001)$ than that of the female soccer players at $18.1 \pm 2.1 \%$.

The comparison of the playing positions revealed an overall highly significant anthropometric difference between the goalkeepers and the midfielders as well as between the defenders and the forwards. Differences were mainly found in the larger body height, shoulder and hand width, chest depth, circumferences and the higher body weight of the goalkeepers. The body fat content (in $\%$ and $\mathrm{kg}$ ) was not significantly different. The defenders, midfielders and the forwards were homogeneous between the groups. 


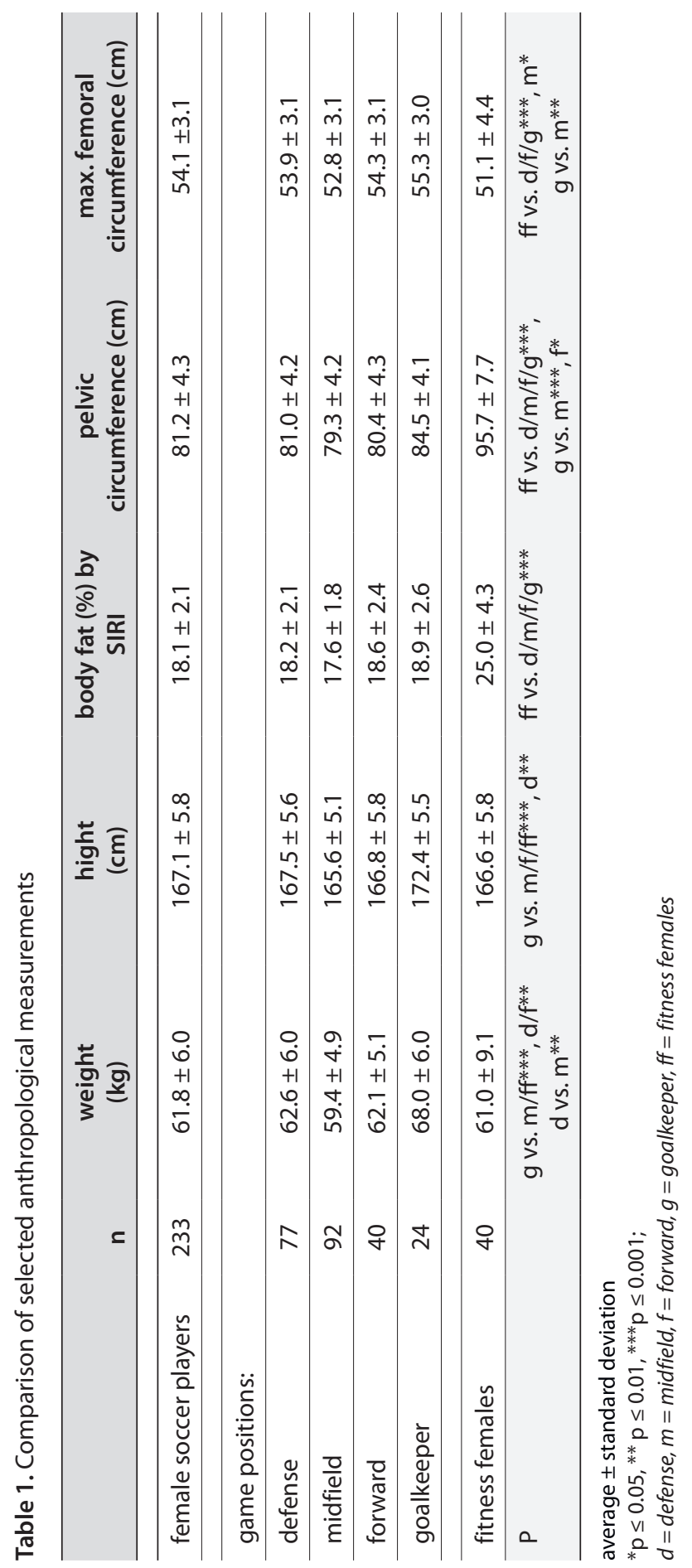




\subsection{Constitutional typologies}

\subsubsection{Heath and Carter somatotyping}

When comparing by somatotypes according to Heath and Carter [9], the fitness females fall into the mesoendomorphic area. Their average endomorphy $(5.8 \pm 1.3)$ is significantly higher $(\mathrm{p} \leq 0.001)$ than that of the female soccer players (defense $=3.4 \pm 0.8$, midfield $=3.2 \pm 0.8$, forward $=3.6 \pm 0.8$, goalkeeper $=3.6 \pm 0.9)$. Furthermore, their average mesomorphy $(5.1 \pm 1.7)$ is significantly $(\mathrm{p} \leq 0.05)$ above midfielders $(4.5 \pm 1.0)$.

The somatotypes of the female soccer players do not reveal significant differences. The midfielders fall into the balanced-mesomorphic, the defenders, forwards and goalkeepers into the endo-mesomorphic area.

Table 2. Comparison of somatotypes according to Heath and Carter

\begin{tabular}{lclll}
\hline & & endomorhpy & mesomorphy & ectomorphy \\
\hline soccer players & 233 & $3.4 \pm 0.8$ & $4.7 \pm 1.1$ & $2.4 \pm 0.9$ \\
\hline game positions: & & & \\
\hline defense & 77 & $3.4 \pm 0.8$ & $4.7 \pm 1.2$ & $2.4 \pm 0.9$ \\
\hline midfield & 92 & $3.2 \pm 0.8$ & $4.5 \pm 1.0$ & $2.5 \pm 0.8$ \\
\hline forward & 40 & $3.6 \pm 0.8$ & $5.0 \pm 1.2$ & $2.3 \pm 0.9$ \\
\hline goalkeeper & 24 & $3.6 \pm 0.9$ & $4.6 \pm 1.0$ & $2.4 \pm 0.8$ \\
\hline fitness females & 40 & $5.8 \pm 1.3$ & $5.1 \pm 1.7$ & $2.6 \pm 1.1$ \\
\hline$p$ & & $\mathrm{ff} v \mathrm{vs} \mathrm{d} / \mathrm{m} / \mathrm{f} / \mathrm{g}^{* * *}$ & $\mathrm{ff} \mathrm{vs.} \mathrm{m}^{*}$ & \\
\hline
\end{tabular}

average \pm standard deviation

${ }^{*} p \leq 0.05,{ }^{* *} p \leq 0.01,{ }^{* * *} p \leq 0.001$;

$d=$ defense, $m=$ midfield,$f=$ forward,$g=$ goalkeeper,$f f=$ fitness females 


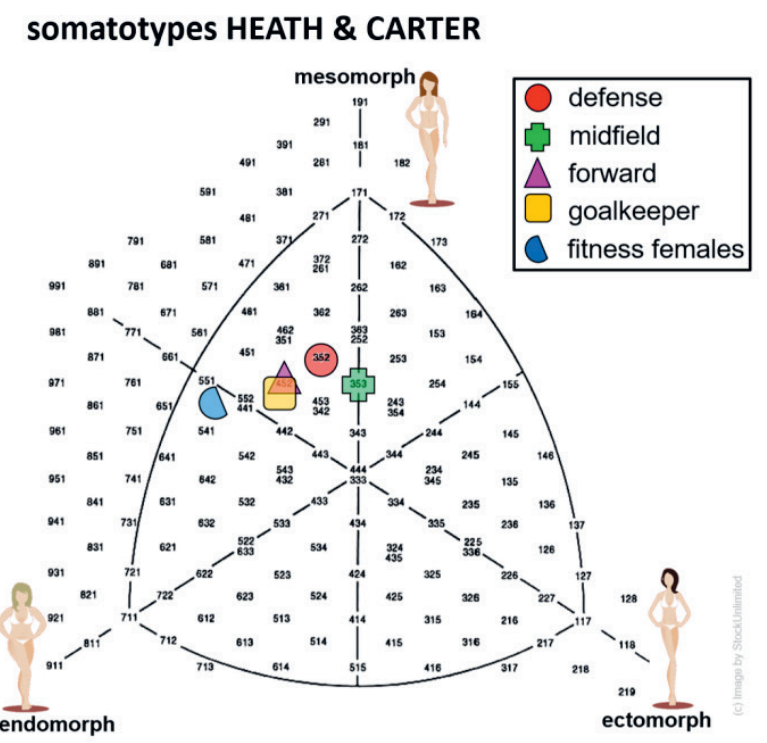

Figure 1. Average somatotype distribution in the somatogram according to Heath and Carter

\subsubsection{Typology according to Conrad}

In Conrad's checkerboard pattern [3], the fitness females show an average in the metromorph/hyperplastic range with a metric index of $-0.6 \pm 0.7$ and plastic index of $79.4 \pm 3.2$. There is a significant difference $(\mathrm{p} \leq 0.01)$ between their metric index and that of the female soccer players. The soccer players are mainly in the leptomorph/ hyperplastic area with an average metric index of $-1.0 \pm 0.4$ and plastic index of $81.2 \pm 3.3$. The goalkeepers $(84.3 \pm 3.2)$ are more hyperplastically pronounced $(\mathrm{p} \leq 0.001)$ than the defenders $(81.5 \pm 3.3)$, the forwards $(81.4 \pm 3.3)$ and the midfielders $(80.0 \pm 3.3)$. 
Table 3. Comparison of Conrad's metric/plastic index

\begin{tabular}{|c|c|c|c|c|}
\hline & \multirow{2}{*}{$\mathbf{n}$} & \multicolumn{3}{|c|}{ Conrad } \\
\hline & & metric index & plastic index & somatotype \\
\hline $\begin{array}{l}\text { female } \\
\text { soccer } \\
\text { players }\end{array}$ & 233 & $-1.0 \pm 0.4$ & $81.2 \pm 3.3$ & leptomorph/hyperplastic \\
\hline \multicolumn{5}{|l|}{$\begin{array}{l}\text { game } \\
\text { positions: }\end{array}$} \\
\hline defense & 77 & $-1.1 \pm 0.4$ & $81.5 \pm 3.3$ & leptomorph/hyperplastic \\
\hline midfield & 92 & $-1.1 \pm 0.4$ & $80.0 \pm 3.3$ & leptomorph/hyperplastic \\
\hline forward & 40 & $-1.0 \pm 0.4$ & $81.4 \pm 3.3$ & leptomorph/hyperplastic \\
\hline goalkeeper & 24 & $-1.0 \pm 0.3$ & $84.3 \pm 3.2$ & leptomorph/hyperplastic \\
\hline $\begin{array}{l}\text { fitness } \\
\text { females }\end{array}$ & 40 & $-0.6 \pm 0.7$ & $79.4 \pm 3.2$ & leptomorph/hyperplastic \\
\hline $\mathrm{p}$ & & $\begin{array}{l}\text { ff vs. } d / m / f^{* * * *} \\
\text { ff vs. } g^{*}\end{array}$ & $\begin{array}{l}g \text { vs. } d / m / f f f^{* * *}, f^{* *} \\
\text { ff vs. } d^{* *}, f^{*} \\
d \text { vs. } m^{*}\end{array}$ & \\
\hline
\end{tabular}

average \pm standard deviation

${ }^{*} p \leq 0.05,{ }^{* *} p \leq 0.01,{ }^{* * *} p \leq 0.001$;

$d=$ defense, $m=$ midfield,$f=$ forward,$g=$ goalkeeper,$f f=$ fitness females

\section{somatotypes CONRAD:}

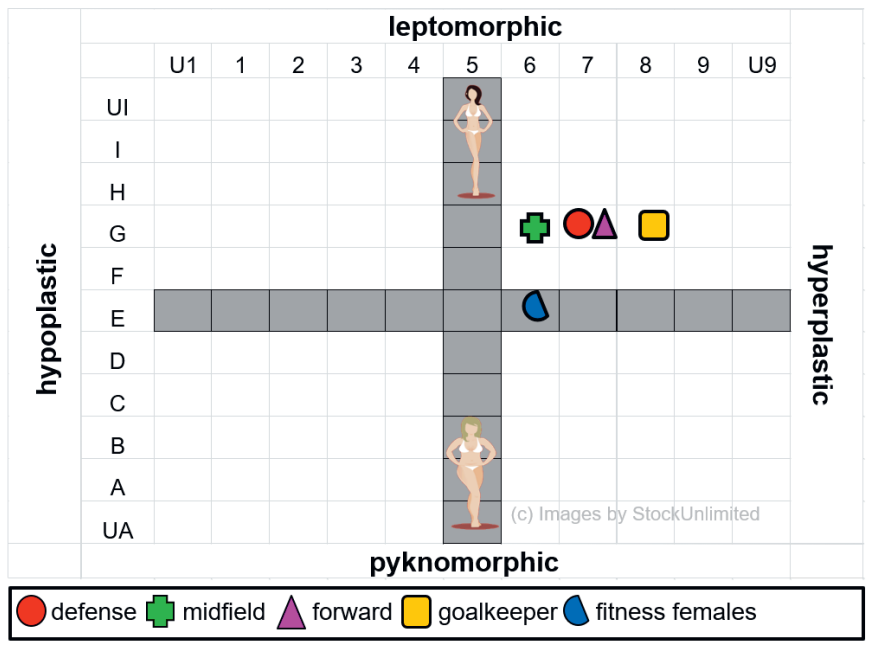

Figure 2. Average type distribution in a checkerboard pattern according to Conrad 


\subsubsection{Typology according to Knussmann}

Knussmann's scatter chart [11] of the fitness females differs from the scatter charts of the female soccer players, but there are no significant data results. The fitness females average L-value $(1.1 \pm 1.6)$ is found in the submacrosom ( 0.5 to 1.4 ) range. Equivalent to the soccer players (defense $=-1.4 \pm 1.2$, midfield $=-1.6 \pm 1.1$, forward $=-1.3 \pm 1.2$, goalkeeper $=-1.2 \pm 1.1$ ), the $\mathrm{D}$-value $(-1.5 \pm 1.2)$ manifests itself between the subleptomorphic $(-1)$ and leptomorphic $(-2)$ area. The average L-value of the midfielders $(1.0 \pm 1.3)$ is also in the submacrosom, the L-value of the defenders $(1.8 \pm 1.7)$ and forwards $(1.7 \pm 1.5)$ are in the macrosom (1.5 to 2.4) and that of the goalkeepers (3.2 \pm 1.4$)$ is found in the supermacrosom (2.5 to 3.4 ) range.

Table 4. Comparison of D-/L-values according to Knussmann

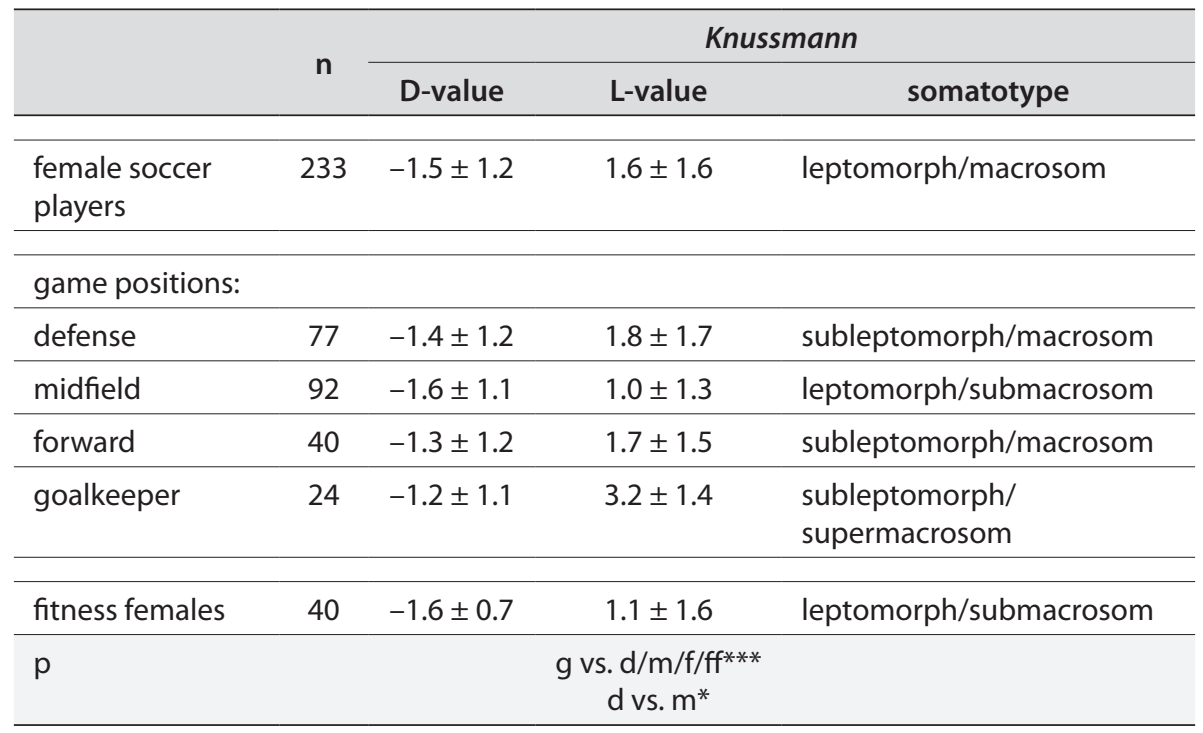

average \pm standard deviation

${ }^{*} p \leq 0.05,{ }^{* *} p \leq 0.01,{ }^{* * *} p \leq 0.001 ; d=$ defense, $m=$ midfield, $f=$ forward, $g=$ goalkeeper, $f f=$ fitness females 


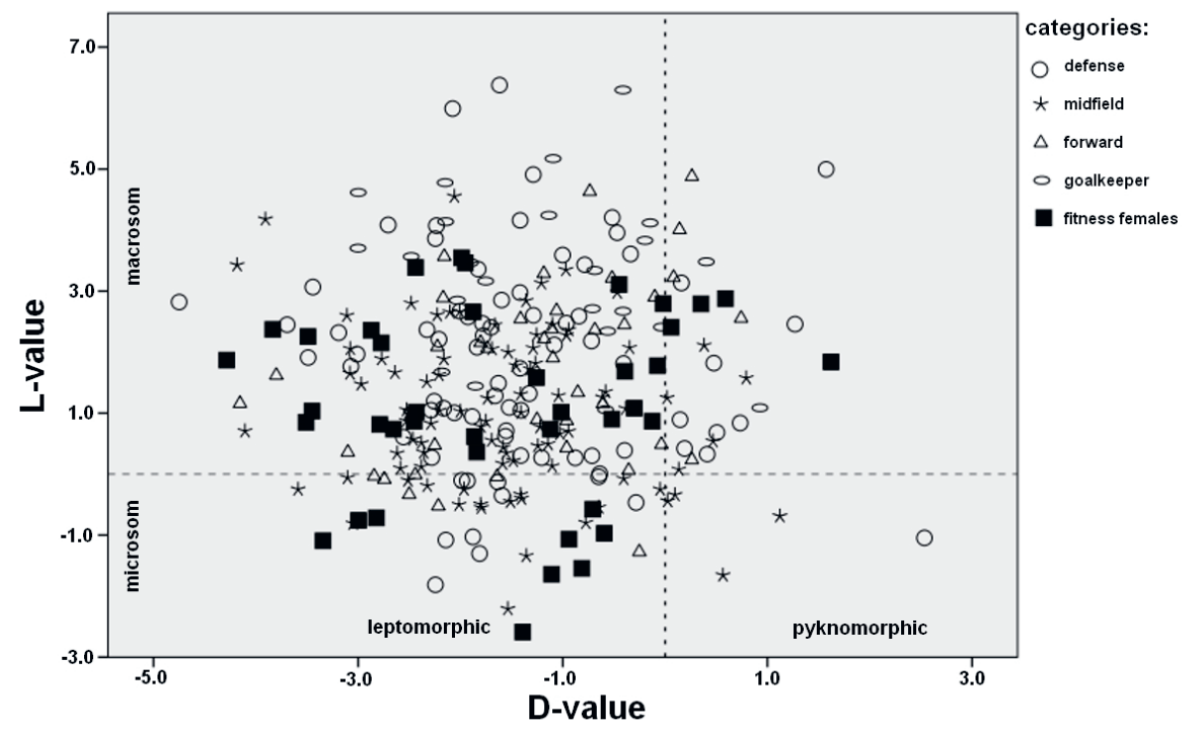

Figure 3. Scatter diagram according to Knussmann per categories

\subsubsection{AKS index}

The AKS index of the fitness females $(0.99 \pm 0.15)$ is significantly lower $(\mathrm{p} \leq$ $0.001)$ than that of the female soccer players $(1.08 \pm 0.09)$ due to their high body fat content.

Table 5. Comparison of AKS index

\begin{tabular}{|c|c|c|}
\hline & $\mathbf{n}$ & AKS index \\
\hline female soccer players & 233 & $1.08 \pm 0.09$ \\
\hline \multicolumn{3}{|l|}{ game positions: } \\
\hline defense & 77 & $1.09 \pm 0.09$ \\
\hline midfield & 92 & $1.08 \pm 0.08$ \\
\hline forward & 40 & $1.09 \pm 0.10$ \\
\hline goalkeeper & 24 & $1.08 \pm 0.09$ \\
\hline fitness females & 40 & $0.99 \pm 0.15$ \\
\hline $\mathrm{p}$ & & $\begin{array}{l}\text { ff vs. } d / m / f^{* * * *} \\
\text { ff vs. } g^{* *}\end{array}$ \\
\hline
\end{tabular}

average \pm standard deviation

${ }^{*} p \leq 0.05,{ }^{* *} p \leq 0.01,{ }^{* * *} p \leq 0.001$;

$d=$ defense, $m=$ midfield,$f=$ forward,$g=$ goalkeeper,$f f=$ fitness females 


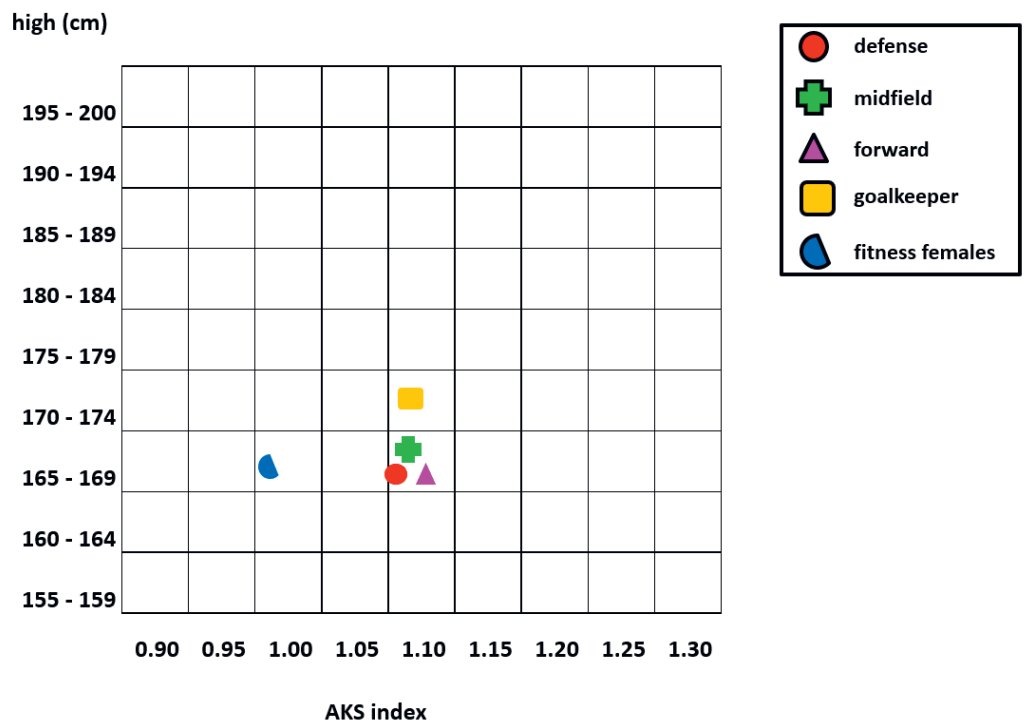

Figure 4. AKS index/body height diagram according to Tittel and Wutscherk

\subsection{5. $B M I$}

No significant differences were found regarding the BMI ( $p>0.05)$.

Table 6. Comparison of the BMI

\begin{tabular}{|c|c|c|}
\hline & $\mathbf{n}$ & BMI $\left(\mathrm{kg} / \mathrm{m}^{2}\right)$ \\
\hline female soccer players & 233 & $22.1 \pm 1.7$ \\
\hline \multicolumn{3}{|l|}{ game positions: } \\
\hline defense & 77 & $22.2 \pm 1.9$ \\
\hline midfield & 92 & $21.6 \pm 1.4$ \\
\hline forward & 40 & $22.4 \pm 1.6$ \\
\hline goalkeeper & 24 & $22.8 \pm 1.7$ \\
\hline fitness females & 40 & $22.0 \pm 2.8$ \\
\hline
\end{tabular}

average \pm standard deviation

${ }^{*} p \leq 0.05,{ }^{* *} p \leq 0.01,{ }^{* * *} p \leq 0.001$ 


\subsection{Sports injuries}
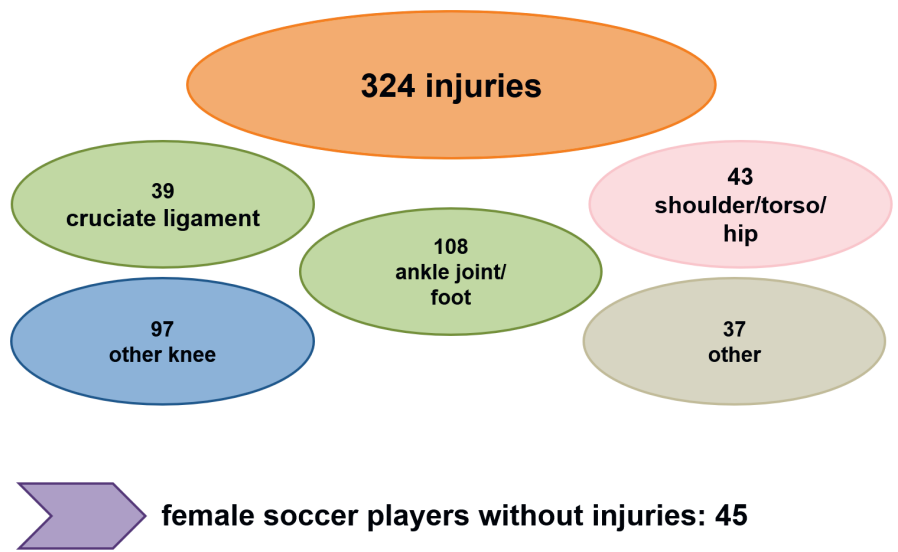

female soccer players without injuries: $\mathbf{4 5}$

Figure 5. Total injuries

A total of 324 injuries occurred to 233 female soccer players during this survey: 39 cruciate ligament injuries (16.7\%), 97 other knee injuries (41.6\%), 108 ankle joint/foot injuries (46.4\%), 43 shoulder/torso/hip injuries (18.5\%) and 37 other injuries (15.9\%). 45 female soccer players were not injured. The review of a possible correlation between the individual playing positions - defense, midfield and forward - and injury type and frequency was negative. According to the results, goalkeepers are suffering significantly $(\mathrm{p} \leq 0.05)$ more "other injuries" (33\%), such as hand, arm and head injuries, compared to the field players $(14 \%)$.

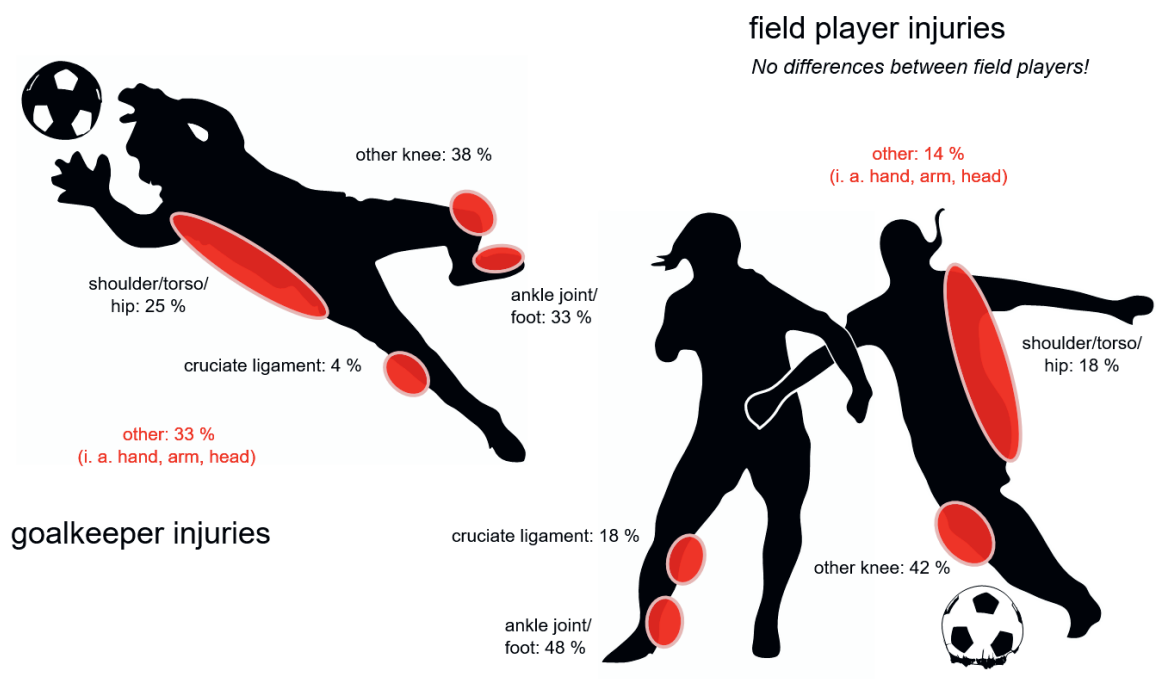

Figure 6. Comparison of injuries by game position 
Regarding the frequency of ankle joint/foot injuries, there was a significant difference between Knussmann's [11] metrosome (38.6 \%) and sub-macrosome constitution types (11.3\%).

The group of female soccer players with a BMI of $25.6-28.0 \mathrm{~kg} / \mathrm{m}^{2}$ suffered significantly ( $\mathrm{p} \leq 0.01)$ more cruciate ligament injuries than the group with a BMI of $20.6-23.0 \mathrm{~kg} / \mathrm{m}^{2}$. All other tests showed no correlation between constitution type and frequency and type of injury.

\section{DISCUSSION}

As assumed, female elite soccer players are physically different from average physically active women (fitness females). This can be attributed to more intense and specific training starting in their youth. The average exercise time of the female soccer players in this study was 25 hours per week. This included strength, endurance and game-specific technique training as well as competition games on the weekends. In comparison, the fitness females have been training in the gym 2-3 times per week for about 1.5 hours for at least two years.

They completed a full-body workout using fitness machines as well as endurance units on the treadmill or the crosstrainer.

Within the female soccer player group, the goalkeepers vary from the field players in respect to their anthropometric measurements. This could surely be the result of play position-specific selection and an increased catching and throwing training. As a logical consequence, large body height results in large height and length measurements of the remaining measurement points. The groups of defenders, midfielders and forwards are very homogeneous with rarely any significant differences. This could be due to the previously mentioned uniform training method and intense load. The requirement profile includes a well-trained speed and jump, accelerating capability and an increased level of agility, manoeuvrability, reaction and anticipation skills. Good endurance capability is a requirement for all playing positions.

No differences can be determined between the playing positions in terms of constitution typology. This could be the result of similar training starting in early youth with the same basic training and volume of exercise for all playing positions [15].

A comparison with the study by Hazir [8] covering a total of 305 male elite soccer players shows that the mesomorphic and ectomorphic values of male and female soccer players are almost identical. Due to higher body fat content, the endomorphic value of the female soccer players is higher. 
Table 7. Comparative game positions of male and female soccer players

\begin{tabular}{|c|c|c|c|c|c|c|c|c|}
\hline & \multicolumn{4}{|c|}{ soccer players (Hazir, 2010) } & \multicolumn{4}{|c|}{$\begin{array}{l}\text { female soccer players (our } \\
\text { study) }\end{array}$} \\
\hline & 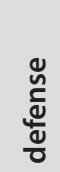 & $\frac{\frac{0}{U}}{\frac{U}{\frac{U}{O}}}$ & $\begin{array}{l}\text { 인 } \\
\text { 인 } \\
\text { 은 }\end{array}$ & 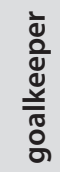 & 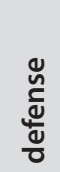 & 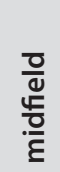 & $\begin{array}{l}\text { 인 } \\
\frac{1}{3} \\
\text { 인 }\end{array}$ & 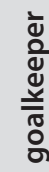 \\
\hline endomorhpy & 2.7 & 2.8 & 2.8 & 2.7 & 3.4 & 3.2 & 3.6 & 3.6 \\
\hline mesomorphy & 4.6 & 4.8 & 4.7 & 4.5 & 4.7 & 4.5 & 5.0 & 4.6 \\
\hline ectomorphy & 2.5 & 2.3 & 2.4 & 2.8 & 2.4 & 2.5 & 2.3 & 2.4 \\
\hline
\end{tabular}

The running routes in the game have lengthened significantly in recent years. Distances of up to $14 \mathrm{~km}$ are covered per game, and the players are on the move $96 \%$ of the time [14]. A study by Jensen and Larsson [1] was able to demonstrate that these findings are valid for both men and women. It was also found that various stress intensity during the game was the same for women and men as a percentage [6]. According to a study by Datson et al. [5], about $1.7 \mathrm{~km}$ of the total running distance in women's soccer is run at a speed of more than $18 \mathrm{~km} / \mathrm{h}$. Elite players are running $28 \%$ more at high speed and $24 \%$ more at sprint speed than medium-level players. Spontaneous braking and starting, sudden changes of direction, etc. are typical stresses during the soccer game. The muscles have to absorb these loads and transmit the kinetic energy physiologically via the myofascial effect chains. Ruptures of the anterior cruciate ligament (ACL) are less common than ankle injuries, but they are much more serious and durable. $70 \%$ of ACL injuries take place without direct interference from the opponent [10].

Soccer players in particular are very likely to tear the other side after an ACL rupture and reconstruction on one side.

Research has also shown that half of the injured players had radiological osteoarthritis signs 15 years after a major knee injury. These were particularly pronounced if the ACL tears were treated conservatively, the injury occurred at an advanced age (over 30 years), and the joint was under stress. The damage is severe if practice of competitive sports is continued. If the menisci are damaged, the optimal damping function in the knee joint as well as the movement execution is no longer guaranteed. The popliteus and semimembranosus muscles may become overburdened. In the event of incomplete healing, micro injuries can result in damage due to the load [4]. 
Compared to the male skeleton, the biggest difference is in the pelvis. In men the pubic branches form an angle of 70-75 degrees and in women an angle of 90-100 degrees. The pelvic blades of women are wide, so that the pelvic entrance is transverse oval and has a larger diameter than in men. These differences in proportion have a negative impact on women when running and jumping because the body's centre of gravity is shifted downwards. Due to the width of the hips, a compensatory physiological valgus position of the knee joints occurs. The femur is subject to increased internal rotation [17]. In the area of the knee joint, the cruciate ligament cavity (notch) is also narrower in women. The condyles have a spherical shape. In general, the joint and ligament apparatus of women is more flexible than that of men. This results in an ability of hyperextension and greater elasticity. As a result, the ligament apparatus is at greater risk of injury. The ligaments of the ankle and the anterior cruciate ligament are particularly affected. The risk for the anterior cruciate ligament is primarily due to the increased risk of trapping external rotation trauma and hyperextension trauma [14]. A reduced joint proprioception results from a generally greater joint and ligament laxity [7]. Many women tend to make changes of direction, stop and start movements with a strong knee extension, which places great stress on the ligaments and reduces the shock-absorbing function of the muscle when braking and the propulsion-generating function when starting [13].

The female skeleton is exposed to greater loads than the male skeleton due to the lower stabilizing muscle mass. So, women display lower strength of the trunk/ pelvic/hip and knee stabilizing muscles [2].

There is evidence that female goalkeepers suffer more "other injuries", such as hand, arm and head injuries, in comparison to field players due to their specific physical stress components. It was not possible to confirm the expected increased injury occurrence of the cruciate ligaments, the knees in general as well as the ankle joint and feet in forward and midfield positions. Due to frequent direction changes, acceleration speed, high running speeds and "noncontact" mechanisms, such as upper body rotation while feet are locked, the physical stress of the lower extremities is exceptionally high [12].

Concerning the frequency of ankle and foot injuries there is a significant difference between the metrosome (38.6\%) and the sub-macrosome group (11.3\%). Since there are no significant differences from the other groups, it is difficult to draw any conclusions from this result.

A significant difference could be found between the number of cruciate ligament injuries at a BMI of $25.6-28.0 \mathrm{~kg} / \mathrm{m}^{2}$ and the number of cruciate liga- 
ment injuries at a BMI of $20.6-23.0 \mathrm{~kg} / \mathrm{m}^{2}$. Soccer players with a higher BMI were found to be more vulnerable to this type of injury than their teammates with a lower BMI. However, this must be viewed critically, since the BMI 25.6$28.0 \mathrm{~kg} / \mathrm{m}^{2}$ group is undersized including only 7 subjects.

According to the present study, playing position, constitution type and BMI are only minor factors for the type and frequency of injury. However, as a large number of injuries occur, there is still a need for further research into improvement of injury prevention in women's soccer.

A starting point could be the inclusion of nutrition and hormone status as well as the increased application of sports motoric tests and preventive examinations. Also, the training design regarding frequency, regeneration and combination of strength, endurance and technique training should be reconsidered and optimized.

\section{REFERENCES}

1. Bangsbo J. (1993). Physiology of Soccer: With Special Reference to Intermittent Exercise. Copenhagen University: August Krogh Institute.

2. Brophy R.H., Chiaia T.A., Maschi R., Dodson C.C., Oh L.S., Lyman S., Allan A.A., Williams R.J. (2009). The core and hip in soccer athletes compared by gender. Stuttgart: International Journal of Sports Medicine, 30(9), 663-667. https://doi.org/10.1055/s-0029-1225328

3. Conrad K. (1963). Der Konstitutionstypus. Berlin: Springer Verlag.

4. Corts M., Harmsel I. (2013). Sportosteopathie: Myofasziale Ketten bei Überlastungssyndromen. Stuttgart.

5. Datson N., Hulton A., Andersson H., Lewis T., Weston M., Drust B., Gregson W. (2014). Applied physiology of female soccer: an update. Sports Medicine, 44(9), 1225-1240. https://doi.org/10.1007/s40279-014-0199-1

6. Davis J., Brewer J. (1993). Applied physiology of female soccer players. Auckland: Sports Medicine, 3, 180-189. https://doi.org/10.2165/00007256-199316030-00003

7. Dick R., Arendt E.A. (1995). Knee injury patterns among men and women in collegiate basketball and soccer. NCAA data and review of literature. Baltimore: The American Journal of Sports Medicine, 23(6), 694-701. https://doi. org/10.1177/036354659502300611

8. Hazir T. (2010). Physical characteristics and somatotype of soccer players according to playing level and position. Journal of Human Kinetics, 26, 83-95. https://doi.org/10.2478/v10078-010-0052-z

9. Heath B., Carter J. (1990). Somatotyping - development and application. Cambridge: Cambridge University Press. 
10. Jöllenbeck T., Neuhaus D., Grebe B., Röckel M. (2010). Verletzungen des vorderen Kreuzbandes - Risikobewertung am Beispiel zweier U17-Mannschaften. Hamburg: Feldhaus Verlag GmbH \& Co. KG.

11. Knussmann R. (1996). Vergleichende Biologie des Menschen. Lehrbuch der Anthropologie und Humangenetik (2. Aufl.). Stuttgart, Jena, Lübeck, Ulm: Gustav Fischer Verlag, 11-17, 123-124, 218-248.

12. Kollrack Y. (2014). Verletzungen im Profifußball: Medizinischer Ausblick auf die Weltmeisterschaft. Berlin: Deutscher Ärzteverlag GmbH, Deutsches Ärzteblatt, 111(22).

13. Nyland J., Albensi R. (1996). Knee injuries in women's soccer - what coaches, players and parents need to know and do. Performance Conditioning Soccer, 2(7), 2-3.

14. Paul M., Gaulrapp H., Zenker H. (2010). Verletzungen im Frauenfußball Analyse retrospektiv und prospektiv erhobener Daten. Rosenheim: Suedwestdeutscher Verlag.

15. Pietsch B. (2013). Positionelle Anforderungen im Fußball - Positionsspezifisches Konditionstraining. Abgerufen am 02. März, 2017. http://www.erfolgsfussballer.de/positionelle-anforderungen-fussball

16. Tittel K., Wutscherk H. (1972). Sportanthropometrie. Leipzig. Barth.

17. Weineck J. (2000). Optimales Training. Leistungsphysiologische Trainingslehre unter besonderer Berücksichtigung des Kinder- und Jugendtrainings. Erlangen: Spitta Verlag GmbH \& Co, 11. Auflage, 19; 82; 123; 456-460.

\section{Address for correspondence:}

Prof. Dr. med. Dr. rer. nat. Dr.Sportwiss. Christoph Raschka

Institute of Sports Sciences, Julius-Maximilians-University, Germany

Judenbühlweg 11

D-97082 Würzburg

E-mail: christoph.raschka@uni-wuerzburg.de 